\title{
Validation strategy can result in an overoptimistic view of the ability of milk infrared spectra to predict methane emission of dairy cattle
}

\author{
Qiuyu Wang and Henk Bovenhuis* \\ Animal Breeding and Genomics Group, Wageningen University, PO Box 338, 6700AH, Wageningen, the Netherlands
}

\begin{abstract}
Because of the environmental impact of methane $\left(\mathrm{CH}_{4}\right)$, it is of great interest to reduce $\mathrm{CH}_{4}$ emission of dairy cattle and selective breeding might contribute to this. However, this approach requires a rapid and inexpensive measurement technique that can be used to quantify $\mathrm{CH}_{4}$ emission for a large number of individual dairy cows. Milk infrared (IR) spectroscopy has been proposed as a predictor for $\mathrm{CH}_{4}$ emission. In this study, we investigated the feasibility of milk IR spectra to predict breath sensor-measured $\mathrm{CH}_{4}$ of 801 dairy cows on 10 commercial farms. To evaluate the prediction equation, we used random and block cross validation. Using random cross validation, we found a validation coefficient of determination $\left(\mathrm{R}^{2} \mathrm{val}\right)$ of 0.49 , which suggests that milk IR spectra are informative in predicting $\mathrm{CH}_{4}$ emission. However, based on block cross validation, with farms as blocks, a negligible $R^{2}$ val of 0.01 was obtained, indicating that milk IR spectra cannot be used to predict $\mathrm{CH}_{4}$ emission. Random cross validation thus results in an overoptimistic view of the ability of milk IR spectra to predict $\mathrm{CH}_{4}$ emission of dairy cows. The difference between the validation strategies could be due to the confounding of farm and date of milk IR analysis, which introduces a correlation between batch effects on the IR analyses and farmaverage $\mathrm{CH}_{4}$. Breath sensor-measured $\mathrm{CH}_{4}$ is strongly influenced by farm-specific conditions, which magnifies the problem. Milk IR wavenumbers from water absorption regions, which are generally considered uninformative, showed moderate accuracy $\left(\mathrm{R}^{2} \mathrm{val}=0.25\right)$ when based on random cross validation, but not when based on block cross validation $\left(\mathrm{R}^{2} \mathrm{val}=0.03\right)$. These results indicate, therefore, that in the current study, random cross validation results in an overoptimistic view on the ability of milk IR spectra to predict $\mathrm{CH}_{4}$ emission. We
\end{abstract}

Received September 13, 2018.

Accepted March 15, 2019.

*Corresponding author: henk.bovenhuis@wur.nl suggest prediction based on wavenumbers from water absorption regions as a negative control to identify potential dependence structures in the data.

Key words: validation strategy, $\mathrm{CH}_{4}$ emission, milk infrared spectroscopy, prediction

\section{INTRODUCTION}

Methane $\left(\mathrm{CH}_{4}\right)$ is emitted by dairy cattle during anaerobic fermentation of feed in the rumen (Gerber et al., 2013). Methane is a potent greenhouse gas and, in this way, dairy production contributes to global warming. In addition, the emitted $\mathrm{CH}_{4}$ accounts for a loss of 2 to $12 \%$ of the gross energy intake of the cow (Johnson and Johnson, 1995). Therefore, there is a need to reduce $\mathrm{CH}_{4}$ emission from dairy cattle and selective breeding might contribute to this (Wall et al., 2010). This approach would require the measurement of $\mathrm{CH}_{4}$ or $\mathrm{CH}_{4}$ indicators on a large number of individual dairy cows.

Several methods have been suggested to quantify $\mathrm{CH}_{4}$ emission from individual dairy cows (Hammond et al., 2016; Negussie et al., 2017). Some studies investigated the possibility of predicting $\mathrm{CH}_{4}$ emission based on milk infrared (IR) spectroscopy (Dehareng et al., 2012; Vanlierde et al., 2015, 2018; Shetty et al., 2017; van Gastelen et al., 2018). Milk IR spectroscopy is a method to analyze milk composition that is widely used to routinely quantify milk fat, protein, and lactose contents. The hypothesized relationship between $\mathrm{CH}_{4}$ emission and milk composition is based on the observation that hydrogen and VFA produced during microbial fermentation in the rumen are both involved in the synthesis pathways of $\mathrm{CH}_{4}$ and de novo milk fatty acids (short- and medium-chain fatty acids). Therefore, milk IR spectra might be used to predict $\mathrm{CH}_{4}$ with the advantage - compared with alternative indicators for $\mathrm{CH}_{4}$ emission - that it can be easily applied on a large scale without substantial cost. Results from studies predicting $\mathrm{CH}_{4}$ emission based on milk IR spectra are not consistent; Vanlierde et al. (2015) reported a validation coefficient of determination $\left(\mathbf{R}^{2} \mathbf{v a l}\right)$ of 0.77 for $\mathrm{CH}_{4}$ production, whereas Shetty et al. (2017) reported a $\mathrm{R}^{2}$ val of 0.13 . These differences warrant further re- 
search into the potential of quantifying $\mathrm{CH}_{4}$ emission of individual cows using milk IR spectra.

A common strategy to evaluate the performance of prediction equations is random cross validation. The idea behind random cross validation is to randomly split the data into a part that is used to build the prediction equation (the calibration set) and a part used to evaluate the performance of the prediction equation (the validation set). When the validation set is independent from the calibration set, cross validation should provide a good estimate of prediction error of the equation when applied to new data. However, several studies in different fields of science have recently pointed at situations in which random cross validation resulted in overoptimistic estimations of predictive ability (Qin et al., 2016; Roberts et al., 2017). Problems with random cross validation might occur when there are dependence structures in the data; in these situations, block cross validation, where data are split strategically instead of randomly and dependence structures are accounted for, can address these problems. The issue of dependence structures might also be relevant for milk IR spectra prediction of traits relevant for dairy; for example, when milk samples on farms are collected and analyzed in batches. Therefore, in this study, we compared results from random cross validation and block cross validation using farms as blocks.

The objective of this study was to investigate the feasibility of milk IR spectra to predict breath sensormeasured $\mathrm{CH}_{4}$ emission of individual dairy cattle on commercial farms using different validation strategies.

\section{MATERIALS AND METHODS}

\section{Methane}

Methane data were collected for 1,508 lactating dairy cows located on 11 commercial dairy farms in the Netherlands between November 2013 and March 2016. The number of cows per farm ranged from 62 to 224 , and more than $85 \%$ of the cows were of the Holstein Friesian breed.

Methane was measured in the breath of cows during milking in automatic milking system (AMS; Lely Astronaut A4, Lely Industries NV, Maassluis, the Netherlands) with nondispersive infrared sensors (Acreo Swedish ICT, Kista, Sweden), a method commonly referred to as the "sniffer method." Sensors were located in the front gate of the AMS, above the feeding trough and at the same level as the cow's nose. In total, 4 different sensors were used during data collection and the sensors were moved from one farm to the other. The sensors measured $\mathrm{CH}_{4}$ concentrations (expressed in ppm) continuously twice per second and these measurements were averaged over the period that a cow visited the AMS. The average $\mathrm{CH}_{4}$ concentrations were $\log _{10}$-transformed to make the trait resemble a normal distribution; the transformed trait will be simply referred to as " $\mathrm{CH}_{4}$ " in the remainder of this article. More details about data collection and definition of the $\mathrm{CH}_{4}$ phenotype are given in van Engelen et al. (2018).

\section{Milk Infrared Spectra}

Milk samples were collected during routine milk production recording for all lactating cows on the 11 commercial dairy farms involved in the current study. Milk recording was on farms with AMS, and milk samples were collected during a cows' visit to the milking unit. Sample collection took place during routine milk recording as implemented by the cooperative cattle improvement organization CRV (Arnhem, the Netherlands). Milk IR spectra were obtained by analyzing the milk samples using Foss FT6000 instruments (Foss Analytical A/S, Hillerød, Denmark) by Qlip B.V. (Zutphen, the Netherlands). Milk IR-predicted fat, protein, and lactose percentages were based on the same milk samples and provided by CRV. Sampling and the performance of analyses are in accordance with the guidelines as set forth by the International Committee for Animal Recording (Rome, Italy).

\section{Data Editing}

The $\mathrm{CH}_{4}$ and milk IR spectra data were combined to build the data set for IR prediction of $\mathrm{CH}_{4}$. All $\mathrm{CH}_{4}$ measurements of a cow for a period ranging from $2 \mathrm{~d}$ before and $2 \mathrm{~d}$ after the date of milk recording (a 5 -d period) were averaged to represent $\mathrm{CH}_{4}$ emission of a cow. Average $\mathrm{CH}_{4}$ was based on 10 to $12 \mathrm{CH}_{4}$ measurements. Using a repeatability of 0.27 (van Engelen et al., 2018), we calculated that $\mathrm{CH}_{4}$ emission of a cow based on the average of 11 repeated measurements can be estimated with $90 \%$ accuracy. Cows with fewer than $5 \mathrm{CH}_{4}$ measurements during the 5-d period were eliminated. Because of this restriction, several cows were eliminated from the data set, including all cows from 1 particular farm. The final data set consisted of 801 cows from 10 commercial farms.

\section{Methane Prediction}

The partial least squares (PLS) regression (Wold et al., 1983) procedure in SAS version 9.3 (SAS Institute, 2011) was used to develop $\mathrm{CH}_{4}$ prediction equations. Milk IR spectra consist of 1,060 individual wavenum- 
bers ranging from 925 to $5,008 \mathrm{~cm}^{-1}$. The spectra were converted from transmittance to absorbance values. In total, 275 individual wavenumbers from 3 spectral regions of milk IR spectra were used to develop prediction equations: 925 to $1,584 \mathrm{~cm}^{-1}, 1,719$ to 1,784 $\mathrm{cm}^{-1}$, and 2,652 to $2,976 \mathrm{~cm}^{-1}$. Wavenumbers in these regions are known to contain most of the information on milk composition (e.g., Capuano et al., 2014) and they will be referred to hereafter as "informative IR wavenumbers."

Wavenumbers from the water absorption regions are generally considered uninformative for predicting milk composition or any other trait. Therefore, we expected that prediction of $\mathrm{CH}_{4}$ based on these wavenumbers would result in negligible prediction accuracy and we considered this prediction to be a negative control. Based on results from Wang et al. (2016), we selected wavenumbers from the water absorption regions, which contain negligible information on milk composition. In total, 114 wavenumbers from 1,623 to $1,670 \mathrm{~cm}^{-1}, 3,166$ to $3,254 \mathrm{~cm}^{-1}, 3,285$ to $3,463 \mathrm{~cm}^{-1}$, and 3,547 to 3,659 $\mathrm{cm}^{-1}$ were selected. based on the following criteria: they should not be significantly affected by systematic environmental effects (except for date of IR analysis), they should not be significantly affected by DGAT1 genotype, and more than $90 \%$ of the variation should be unexplained (residual variance).

A commonly used negative control is permutation of the data. To gain further insight into the IR prediction of $\mathrm{CH}_{4}$, we performed 2 additional permutation analyses. First, we randomly assigned the milk IR spectra to cows in the whole data set. Second, the data were permuted by randomly assigning milk IR spectra to another cow within the same farm. The permuted IR data were used to predict $\mathrm{CH}_{4}$ based on selected wavenumbers from the water absorption regions or based on informative IR wavenumbers. Both permutation strategies were repeated 10 times.

The optimal number of latent variables for the PLS prediction equation was determined based on the lowest root mean squared error of a 10 -fold cross validation procedure using the CVTEST option in PROC PLS in SAS 9.3 (SAS Institute, 2011). The optimal number of latent variables was 15 for the 275 informative IR wavenumbers and 4 for the 114 wavenumbers from the water absorption regions; these values were used as input for building the $\mathrm{CH}_{4}$ prediction equations.

Fat, protein, and lactose percentages are milk composition traits that are routinely collected and predicted based on milk IR measurements and might contain information on $\mathrm{CH}_{4}$. Because there is interest in the additional information that might be available in the full milk IR spectra for predicting $\mathrm{CH}_{4}$, we also predicted
$\mathrm{CH}_{4}$ based on these routinely collected milk composition traits.

\section{Validation Strategies}

For the described methane prediction, we applied 2 validation strategies: random cross validation and block cross validation with farms as blocks. The commonly used random cross validation refers to a strategy in which the samples are randomly assigned to a calibration or a validation set. This procedure is repeated and results are averaged. In the current study, 640 cows $(\sim 80 \%)$ were randomly assigned to the calibration set and 161 cows $(\sim 20 \%)$ to the validation set and the procedure was repeated 50 times. The averaged coefficient of determination based on the calibration samples $\left(\mathbf{R}^{2} \mathbf{c a l}\right)$ was calculated along with root mean squared error of calibration (RMSEC). The validation samples were used to calculate $R^{2}$ val and the validation mean squared error of prediction (RMSEP).

In the block cross validation strategy, samples were assigned to a calibration or validation set based on the farm from which the samples were taken. In the current study, the calibration set consisted of 9 farms and the validation set consisted of samples from the remaining farm. This procedure was repeated 10 times such that samples from each farm were validated based on the prediction equation that was calibrated based on data from the other 9 farms.

\section{Repeated Observations}

Several studies that predicted $\mathrm{CH}_{4}$ emission based on milk composition used data that included repeated observations on the same cow (e.g., Dehareng et al., 2012). Consequently, when using random cross validation, different samples from the same cow might be present in both the calibration and the validation sets. This might affect the evaluation of the prediction equation because it creates dependencies between calibration and validation sets. Therefore, we also constructed $\mathrm{CH}_{4}$ prediction equations based on cows with repeated observations. A second milk recording was available on 4 of the 10 farms. In total, 234 cows had repeated $\mathrm{CH}_{4}$ and milk IR observations available and these 468 observations were used in this analysis. The repeated observations had the same data editing procedure as described above. The number of cows on each of the 4 farms ranged from 39 to 92 . The time interval between 2 observations (2 routine milk recordings) of a cow was approximately $1 \mathrm{mo}$. Observations that were collected first were assigned to the calibration set and those that were collected later were assigned to the validation set. 
Table 1. Evaluation of $\log _{10}$-transformed $\mathrm{CH}_{4}$ prediction using random cross validation and block cross validation ${ }^{1}$

\begin{tabular}{|c|c|c|c|c|c|c|c|c|}
\hline Predictor & \multicolumn{4}{|c|}{ Random cross validation ${ }^{2}$} & \multicolumn{4}{|c|}{ Block cross validation ${ }^{3}$} \\
\hline$\overline{\text { Fat } \%+\text { Prot } \%+\text { Lact } \%}{ }^{4}$ & 0.02 & 0.02 & 0.265 & 0.266 & 0.02 & 0.04 & 0.263 & 0.266 \\
\hline Infrared water absorption $^{6}$ & 0.32 & 0.25 & 0.221 & 0.233 & 0.33 & 0.03 & 0.217 & 0.309 \\
\hline
\end{tabular}

${ }^{1} \mathrm{R}^{2}$ cal $=$ coefficient of determination for calibration; $\mathrm{R}^{2} \mathrm{val}=$ coefficient of determination for validation; RMSEC $=$ root mean squared error of calibration; RMSEP = root mean squared error of validation.

${ }^{2}$ Results are averaged from 50 replicates.

${ }^{3}$ Results are averaged from 10 replicates, and in each replicate, samples from 1 farm were validated by samples from the other 9 farms.

${ }^{4}$ Fat, protein, and lactose percentages.

${ }^{5}$ Infrared informative: 275 individual wavenumbers from 3 spectral regions from 925 to $1,584 \mathrm{~cm}^{-1}, 1,719$ to $1,784 \mathrm{~cm}^{-1}$, and 2,652 to $2,976 \mathrm{~cm}^{-1}$. ${ }^{6}$ Infrared water absorption: selected set of 114 wavenumbers from the water absorption regions from 1,623 to $1,670 \mathrm{~cm}^{-1}, 3,166$ to $3,254 \mathrm{~cm}^{-1}$, 3,285 to $3,463 \mathrm{~cm}^{-1}$, and 3,547 to $3,659 \mathrm{~cm}^{-1}$.

\section{RESULTS}

\section{Descriptive Statistics}

The average $\log _{10}$-transformed $\mathrm{CH}_{4}$ based on all 801 records from the first sampling period was 2.250 with a standard deviation of 0.267 . The number of records per farm ranged from 34 to 116 . We detected substantial differences between farms in average $\log _{10}$-transformed $\mathrm{CH}_{4}$ (ranging from 2.026 to 2.657), and the within-farm standard deviation (ranging from 0.072 to 0.188 ) was substantially smaller than that based on all records (0.267). The Pearson correlation coefficients between $\mathrm{CH}_{4}$ and routinely recorded milk production traits were generally low: 0.03 for fat percentage, 0.07 for protein percentage, and -0.14 for lactose percentage. Pearson correlations between $\mathrm{CH}_{4}$ and each of the 275 informative IR wavenumbers ranged from -0.17 to 0.25 . Pearson correlations between $\mathrm{CH}_{4}$ and each of the 114 wavenumbers from the water absorption regions ranged from -0.23 to 0.29 .

\section{Prediction of Methane}

Performance of the different $\mathrm{CH}_{4}$ prediction equations evaluated using random cross validation and block cross validation is shown in Table 1 . Based on random cross validation, prediction of $\mathrm{CH}_{4}$ based on the routinely recorded milk production traits fat, protein, and lactose percentages was poor $\left(\mathrm{R}^{2} \mathrm{val}=0.02\right)$. Prediction based on 275 informative IR wavenumbers and evaluation using random cross validation indicated moderate prediction accuracy $\left(\mathrm{R}^{2} \mathrm{val}=0.49\right)$. A surprisingly high prediction accuracy was found based on wavenumbers from the water absorption regions $\left(\mathrm{R}^{2} \mathrm{val}=0.25\right)$.

Block cross validation gave a completely different view of the ability to predict $\mathrm{CH}_{4}$ based on milk IR spectra. Prediction based on 275 informative IR wavenumbers showed an $\mathrm{R}^{2}$ val (averaged over 10 replicates) of 0.01 , indicating that the predictive power of milk IR spectra for $\mathrm{CH}_{4}$ is negligible. Results for each of the 10 replicates are shown in Table 2 . In each replicate, samples from one farm were validated based on

Table 2. Descriptive statistics and evaluation of $\log _{10}$ transformed $\mathrm{CH}_{4}$ prediction based on informative infrared wavenumbers and block cross validation ${ }^{1,2}$

\begin{tabular}{|c|c|c|c|c|c|c|c|c|c|c|}
\hline $\begin{array}{l}\text { No. of } \\
\text { cows }\end{array}$ & \multicolumn{3}{|c|}{ Calibration } & RMSEC & $\begin{array}{l}\text { Validated } \\
\text { farm }\end{array}$ & $\begin{array}{l}\text { No. of } \\
\text { cows }\end{array}$ & \multicolumn{3}{|c|}{ Validation } & RMSEP \\
\hline 733 & 2.264 & 0.273 & 0.57 & 0.178 & A & 68 & 2.095 & 0.115 & 0.00 & 0.298 \\
\hline 702 & 2.209 & 0.258 & 0.54 & 0.175 & $\mathrm{C}$ & 99 & 2.542 & 0.105 & 0.00 & 0.363 \\
\hline 733 & 2.253 & 0.275 & 0.67 & 0.159 & D & 68 & 2.216 & 0.156 & 0.01 & 0.516 \\
\hline 729 & 2.262 & 0.272 & 0.57 & 0.178 & $\mathrm{E}$ & 72 & 2.128 & 0.174 & 0.03 & 0.266 \\
\hline 749 & 2.222 & 0.253 & 0.62 & 0.155 & $\mathrm{H}$ & 52 & 2.653 & 0.080 & 0.03 & 0.714 \\
\hline 685 & 2.288 & 0.269 & 0.53 & 0.183 & I & 116 & 2.026 & 0.094 & 0.00 & 0.438 \\
\hline 692 & 2.264 & 0.283 & 0.57 & 0.184 & $\mathrm{~J}$ & 109 & 2.160 & 0.093 & 0.00 & 0.128 \\
\hline
\end{tabular}

${ }^{1}$ Mean = averaged $\log _{10}$-transformed $\mathrm{CH}_{4} ; \mathrm{R}^{2} \mathrm{cal}=$ coefficient of determination for calibration; $\mathrm{R}^{2}$ val = coefficient of determination for validation; RMSEC $=$ root mean squared error of calibration; RMSEP $=$ root mean squared error of validation .

${ }^{2}$ Results are shown for each of the 10 replicates where records from one of the farms are used for validation. 
the prediction equation that was calibrated based on samples from the other 9 farms. The $\mathrm{R}^{2}$ val ranged from 0.00 to 0.03 , whereas $\mathrm{R}^{2}$ cal ranged from 0.53 to 0.67 . These results show that the small $\mathrm{R}^{2}$ val was not due to specific conditions on just one or a few farms.

Block cross validation also resulted in low prediction accuracy based on wavenumbers from the water absorption regions (Table $1, \mathrm{R}^{2} \mathrm{val}=0.03$ ). The $\mathrm{R}^{2}$ val based on block cross validation for routinely recorded milk production traits fat, protein, and lactose percentages was negligible $\left(R^{2}\right.$ val $\left.=0.04\right)$ and in line with results obtained using random cross validation.

When IR spectra were permuted and IR spectra were randomly assigned to cows in the data set, random cross validation resulted in $\mathrm{R}^{2} \mathrm{val}<0.01$, for prediction equations based on both informative IR wavenumbers and wavenumbers from the water absorption regions. However, when IR spectra were randomly assigned to another cow on the same farm, random cross validation resulted in an average $R^{2}$ val of 0.44 based on informative wavenumbers and $R^{2}$ val of 0.23 based on wavenumbers from water absorption regions. When using block cross validation, $\mathrm{R}^{2}$ val was negligible for all combinations studied; that is, informative IR wavenumbers or wavenumbers from the water absorption regions and random or within herd permutation.

\section{Repeated Observations}

Results for validation of $\mathrm{CH}_{4}$ prediction based on repeated observations of the same cow are shown in Table 3 . The predictions were based on 275 informative IR wavenumbers and validation was based on 1 replicate. Results are presented for each farm separately as well as based on all 234 cows. For each prediction, we found a large discrepancy between $\mathrm{R}^{2}$ val and corresponding $\mathrm{R}^{2}$ cal. For individual farms, the $\mathrm{R}^{2}$ val for $\mathrm{CH}_{4}$ ranged from 0.10 to 0.21 . Based on data from all 234 cows, the $\mathrm{R}^{2}$ val for $\mathrm{CH}_{4}$ was 0.07 .

Table 3. Prediction of repeated observations on the farms with 2 measurements of $\log _{10}$-transformed $\mathrm{CH}_{4}$ and milk infrared spectra ${ }^{1,2}$

\begin{tabular}{lccccc}
\hline Farm & $\begin{array}{c}\text { No. of } \\
\text { cows }\end{array}$ & $\mathrm{R}^{2}$ cal & $\mathrm{R}^{2}$ val & RMSEC & RMSEP \\
\hline $\mathrm{A}$ & 58 & 0.77 & 0.10 & 0.057 & 0.526 \\
$\mathrm{C}$ & 45 & 0.72 & 0.10 & 0.047 & 0.277 \\
$\mathrm{H}$ & 39 & 0.78 & 0.21 & 0.037 & 0.850 \\
$\mathrm{~J}$ & 92 & 0.63 & 0.19 & 0.066 & 0.094 \\
Total & 234 & 0.81 & 0.07 & 0.109 & 0.364 \\
\hline
\end{tabular}

${ }^{1} \mathrm{R}^{2}$ cal $=$ coefficient of determination for calibration; $\mathrm{R}^{2}$ val $=$ coefficient of determination for validation; RMSEC = root mean squared error of calibration; RMSEP = root mean squared error of validation.

${ }^{2}$ Results are based on 1 replicate. Prediction equations were developed on the first collected samples and validated on the later collected samples.

\section{DISCUSSION}

In this study, we investigated the feasibility of milk IR spectra for predicting breath sensor-measured $\mathrm{CH}_{4}$ emission of individual dairy cows on commercial farms. The $\mathrm{CH}_{4}$ prediction was evaluated using different validation strategies. Results from random cross validation suggested a moderate prediction accuracy $\left(\mathrm{R}^{2} \mathrm{val}=\right.$ 0.49 ), whereas block cross validation with farms as blocks indicated that milk IR spectra cannot be used to predict $\mathrm{CH}_{4}$ emission $\left(\mathrm{R}^{2} \mathrm{val}=0.01\right)$. Wavenumbers from water absorption regions are commonly assumed to contain no information on milk composition; however, these wavenumbers resulted in a $\mathrm{R}^{2}$ val of 0.25 for $\mathrm{CH}_{4}$ based on random cross validation, whereas a $\mathrm{R}^{2}$ val of 0.03 was obtained based on block cross validation. These results indicate that random cross validation leads to an overoptimistic view of the ability of milk IR spectra to predict $\mathrm{CH}_{4}$ emission of individual dairy cows.

\section{Validation Strategy}

The current study showed large differences in results between random cross validation and block cross validation. Random cross validation has been commonly applied in studies that use milk IR spectra to predict $\mathrm{CH}_{4}$ emission (e.g., Dehareng et al., 2012; Shetty et al., 2017) or other traits of dairy cows (e.g., Soyeurt et al., 2006; Rutten et al., 2009). However, in the current study, we showed that random cross validation can lead to misleading conclusions. Qin et al. (2016) indicate that random cross validation underestimates the error rate of the prediction equation when predictors are analyzed in batches and there are systematic differences between batches. In the current study, $\mathrm{CH}_{4}$ measurements were taken by installing breath sensors consecutively on different farms. Milk samples were collected on these farms during routine milk production recording. Consequently, milk IR analyses of all milk samples collected from a farm were performed on the same day and probably using the same spectrometer, whereas milk samples from different farms were analyzed on different days and possibly using different spectrometers. Consequently, systematic differences between the date of milk IR analysis, which might include differences between spectrometers, are confounded with farm. Grelet et al. (2015) showed the importance of differences between spectrometers. Furthermore, Wang et al. (2016) showed significant effects for date of milk IR analysis, and the time trend in milk IR wavenumbers indicates instability of the spectrometer over time. Confounding of farm with the date of milk IR analysis results in errors associated with the date of milk IR analysis being 
correlated with average $\mathrm{CH}_{4}$ emission of a farm. The problem is illustrated by prediction of $\mathrm{CH}_{4}$ based on wavenumbers from the water absorption regions, which resulted in a $R^{2}$ val of 0.25 . These wavenumbers show highly significant effects for the date of milk IR analysis (Wang et al., 2016) and contain negligible information on the actual milk composition. Because of this confounding, wavenumbers from the water absorption regions explained part of the between-herd variation in $\mathrm{CH}_{4}$ emission. Correlations due to confounding of farm and date of milk IR analysis will not be transmitted to new data points and are spurious. These correlations are broken down in block cross validation with farms as blocks; however, they remain undetected when using random cross validation and thus random cross validation will lead to wrong conclusions. Similar discrepancies between validation strategies have been reported in other fields of science (Gasch et al., 2015; Roberts et al., 2017; Meyer et al., 2018). Burman et al. (1994) conducted simulations on dependent observations and showed that classical leave-one-out cross validation can be misleading. They also demonstrated that blocking adapts cross validation to dependency by allowing near independence between calibration and validation sets.

Based on largely the same data as used in the current study, van Engelen et al. (2018) determined that $56 \%$ of the total variation in $\mathrm{CH}_{4}$ can be explained by the interaction of day of $\mathrm{CH}_{4}$ measurement and AMS, which reflects mainly variation between farms. The sniffer method used in the current study to quantify $\mathrm{CH}_{4}$ is known to be affected by specific farm conditions such as airflow patterns and barn management (Wu et al., 2016). Differences in $\mathrm{R}^{2}$ val between the validation strategies are directly related to the magnitude of the between-farm variation in $\mathrm{CH}_{4}$ emission.

Prediction of $\mathrm{CH}_{4}$ based on fat, protein, and lactose percentages suggests that no information of breath $\mathrm{CH}_{4}$ emission is captured by routinely recorded milk composition traits. Interestingly, there was no discrepancy between the validation strategies, as both $R^{2}$ val were negligible. This indicates that batch effects on IR analyses do not affect IR-predicted fat, protein, and lactose percentages; the signal-to-noise ratio of "date of milk IR analysis" does not affect all IR wavenumbers to the same extent.

\section{Negative Control}

Situations might exist in which confounding effects of batch analyses are not immediately obvious. To identify potential problems, we therefore recommend prediction based on wavenumbers from the water absorption regions as a negative control. This assumes that wavenumbers from the water absorption regions contain negligible information on milk composition. Previously, Wang et al. (2016) showed that some of the wavenumbers from the water absorption regions are significantly affected by the DGAT1 polymorphism and by lactation stage, suggesting that these wavenumbers do contain information regarding milk composition. When we included these wavenumbers in the prediction, we obtained a random cross validation $\mathrm{R}^{2}$ val of 0.34 , which is considerably higher than the value of 0.25 (Table 1). This underlines the importance of carefully selecting wavenumbers from the water absorption regions when used as a negative control.

We performed different permutation analyses where milk IR spectra were randomly assigned to cows in the data set or to another cow within the same farm. The second permutation strategy did not affect herd $\mathrm{CH}_{4}$ averages; therefore, these results confirm that errors associated with date of milk IR analysis are correlated with average farm $\mathrm{CH}_{4}$ emission. Batch effects on the IR analyses explain differences in $\mathrm{CH}_{4}$ between farms. The permutation analysis provides further insight into the problem but will not necessarily be able to identify the problem; that is, confounding. Including prediction based on wavenumbers from the water absorption regions is a way to detect potential problems.

\section{Literature}

Several studies have investigated the feasibility of predicting $\mathrm{CH}_{4}$ emission for individual cows based on milk IR spectra. The reported random cross validation $\mathrm{R}^{2}$ val ranged from 0.13 (Shetty et al., 2017) to 0.77 (Vanlierde et al., 2015). These large differences between studies can be partly explained by differences in methods used to quantify $\mathrm{CH}_{4}$ emission: some studies used respiration chambers (van Gastelen et al., 2018; Vanlierde et al., 2018), whereas others used sulfur hexafluoride $\left(\mathrm{SF}_{6}\right)$ tracer (Dehareng et al., 2012; Vanlierde et al., 2015) or the sniffer method (Shetty et al., 2017). Shetty et al. (2017) used the sniffer method, which is similar to the $\mathrm{CH}_{4}$ measuring method used in the current study, and reported a $\mathrm{R}^{2}$ val based on random cross validation of 0.13 , considerably lower than the value of 0.49 we found using the same validation strategy. Therefore, the spurious results obtained based on random cross validation in the current study seem less severe in the study by Shetty et al. (2017). This might be because Shetty et al. (2017) averaged the IR spectra over multiple milk samples. It is expected that averaging milk IR spectra, when analyzed in different batches, will reduce "date of IR analysis" effects. In addition, differences in $\mathrm{CH}_{4}$ emission between farms might be smaller in Shetty et al. (2017) than in the current study. Shetty et al. (2017) used data from 3 
farms and performed an additional calibration based on data from an experimental farm while validating based on commercial farm data, which is identical to the block cross validation we propose here. This block validation strategy showed negligible $\mathrm{R}^{2} \mathrm{val}$ and the authors concluded that variation in commercial farm data is not included in the experimental data (Shetty et al., 2017). Most studies have used random cross validation to evaluate the prediction of $\mathrm{CH}_{4}$ emission based on milk IR spectra (Dehareng et al., 2012; Vanlierde et al., 2015, 2018; van Gastelen et al., 2018). Results from the current study indicate that random cross validation results in an overoptimistic view of the ability of milk IR spectra to predict $\mathrm{CH}_{4}$ emission; therefore, results presented in the aforementioned studies might be too optimistic. However, this is only the case under specific conditions. The description of the data in most studies does not allow conclusions to be drawn about whether, and to what extent, the results reported are affected by the validation strategy. In several situations, however, confounding might be an issue but not immediately obvious; for example, confounding of batch effects of IR analyses and $\mathrm{CH}_{4}$ measured in respiration chambers. Respiration chambers are regarded as the gold standard and one might conclude that $\mathrm{CH}_{4}$ measurements from respiration chambers are not influenced by location- or experiment-specific conditions, as is the case for farms in the current study. However, results from respiration chambers in a study in the UK showed large between-chamber variation (Gardiner et al., 2015). Therefore, confounding of respiration chamber and milk IR analysis might also lead to an overoptimistic view of the ability of milk IR spectra to predict $\mathrm{CH}_{4}$ emission. To identify potential problems, wavenumbers from the water absorption regions can be used as a negative control.

Several studies have shown that milk IR spectra can be used to predict a wide variety of traits such as milk fat composition (e.g., Soyeurt et al., 2006; Rutten et al., 2009), milk protein composition (Bonfatti et al., 2011; Rutten et al., 2011), milk coagulation, and ketone bodies and energy status of dairy cows (McParland et al., 2011; De Marchi et al., 2014). All of these studies based their conclusions on random cross validation and, as shown in the current study, this might lead to overoptimistic conclusions under certain conditions. Studies by Rutten et al. (2009, 2011) involved almost 400 farms, and milk samples from approximately 20 farms were analyzed on the same day. Therefore, 20 farms were confounded with date of milk IR analysis. Random cross validation might result in overoptimistic $\mathrm{R}^{2} \mathrm{val}$ if the averaged milk fat or milk protein composition for these farms differed between dates of milk IR analysis. This is unlikely and was confirmed by analysis of the negative control (results not shown).

\section{Predicting on Repeated Observations}

The differences between random and block cross validations indicate that we obtained an overoptimistic result when both calibration and validation data sets contained samples from the same farms. To investigate whether the presence of the same cows in both calibration and validation sets affects evaluation of the prediction equation, we performed additional analyses using the repeated observations. As shown in Table 3, the $\mathrm{R}^{2}$ val were between 0.10 and 0.21 for individual farms and 0.07 when based on all cows with repeated observations. These values were low but higher than the block cross validation $\mathrm{R}^{2}$ val of 0.04 . Although these results are based on a small number of observations and only one replicate, they suggest that having repeated observations on the same cow is a lesser problem than the issue related to confounding of farm and date of milk IR analysis. However when multiple observations per cow are available, the validation strategy should take this into account (Shetty et al., 2017; Vanlierde et al., 2018).

\section{CONCLUSIONS}

We investigated the feasibility of milk IR spectra to predict breath sensor-measured $\mathrm{CH}_{4}$ emission of dairy cows on commercial farms in the Netherlands using different validation strategies. We showed that random cross validation could result in an overoptimistic view on the ability of milk IR spectra to predict $\mathrm{CH}_{4}$ emission. This is due to confounding of farm and date of milk IR analysis. Whether adjusting for date of milk IR analysis can avoid these issues requires further investigations. To identify dependence structures in the data, we recommend prediction based on wavenumbers from the water absorption regions as a negative control. The negligible prediction accuracy of $\mathrm{CH}_{4}$ emission based on block cross validation with farms as blocks indicated that milk IR spectra cannot be used to predict breath sensor-measured $\mathrm{CH}_{4}$ of dairy cows.

\section{ACKNOWLEDGMENTS}

The authors acknowledge the China Scholarship Council for funding the PhD project of Qiuyu Wang, Qlip B.V. (Zutphen, the Netherlands) for the milk IR spectra, CRV (Cooperative cattle improvement organization, Arnhem, the Netherlands) for providing data of dairy cows, and the 11 farmers for their collaboration. 
Data used in this project were obtained from the TI Food and Nutrition (Wageningen, the Netherlands) program "Reduced methane emissions from dairy cows: towards sustainable dairy cattle production by increased understanding of genetic variation and rumen functioning."

\section{REFERENCES}

Bonfatti, V., G. Di Martino, and P. Carnier. 2011. Effectiveness of mid-infrared spectroscopy for the prediction of detailed protein composition and contents of protein genetic variants of individual milk of Simmental cows. J. Dairy Sci. 94:5776-5785.

Burman, P., E. Chow, and D. Nolan. 1994. A cross-validatory method for dependent data. Biometrika 81:351-358.

Capuano, E., J. Rademaker, H. van den Bijgaart, and S. M. van Ruth. 2014. Verification of fresh grass feeding, pasture grazing and organic farming by FTIR spectroscopy analyses of bovine milk. Food Res. Int. 60:59-65.

De Marchi, M., V. Toffanin, M. Cassandro, and M. Penasa. 2014 Invited review: Mid-infrared spectroscopy as phenotyping tool for milk traits. J. Dairy Sci. 97:1171-1186.

Dehareng, F., C. Delfosse, E. Froidmont, H. Soyeurt, C. Martin, N. Gengler, A. Vanlierde, and P. Dardenne. 2012. Potential use of milk mid-infrared spectra to predict individual methane emission of dairy cows. Animal 6:1694-1701.

Gardiner, T. D., M. D. Coleman, F. Innocenti, J. Tompkins, A. Connor, P. C. Garnsworthy, J. M. Moorby, C. K. Reynolds, A. Waterhouse, and D. Wills. 2015. Determination of the absolute accuracy of UK chamber facilities used in measuring methane emissions from livestock. Measurement 66:272-279.

Gasch, C. K., T. Hengl, B. Gräler, H. Meyer, T. S. Magney, and D. J. Brown. 2015. Spatio-temporal interpolation of soil water, temperature, and electrical conductivity in 3D+ T: The Cook Agronomy Farm data set. Spat. Stat. 14:70-90.

Gerber, P. J., H. Steinfeld, B. Henderson, A. Mottet, C. Opio, J. Dijkman, A. Falcucci, and G. Tempio. 2013. Tracking Climate Change Through Livestock-A Global Assessment of Emissions and Mitigation Opportunities. Food and Agriculture Organization of the United Nations, Rome, Italy.

Grelet, C., J. F. Pierna, P. Dardenne, V. Baeten, and F. Dehareng. 2015. Standardization of milk mid-infrared spectra from a European dairy network. J. Dairy Sci. 98:2150-2160.

Hammond, K. J., L. A. Crompton, A. Bannink, J. Dijkstra, D. R. Yáñez-Ruiz, P. O'Kiely, E. Kebreab, M. A. Eugène, Z. Yu, K. J. Shingfield, A. Schwarm, A. N. Hristov, and C. K. Reynolds. 2016. Review of current in vivo measurement techniques for quantifying enteric methane emission from ruminants. Anim. Feed Sci. Technol. 219:13-30.

Johnson, K. A., and D. E. Johnson. 1995. Methane emissions from cattle. J. Anim. Sci. 73:2483-2492.

McParland, S., G. Banos, E. Wall, M. P. Coffey, H. Soyeurt, R. F. Veerkamp, and D. P. Berry. 2011. The use of mid-infrared spectrometry to predict body energy status of Holstein cows. J. Dairy Sci. 94:3651-3661.

Meyer, H., C. Reudenbach, T. Hengl, M. Katurji, and T. Nauss. 2018. Improving performance of spatio-temporal machine learning models using forward feature selection and target-oriented validation. Environ. Model. Softw. 101:1-9.

Negussie, E., Y. de Haas, F. Dehareng, R. J. Dewhurst, J. Dijkstra, N. Gengler, D. P. Morgavi, H. Soyeurt, S. van Gastelen, T. Yan, and
F. Biscarini. 2017. Invited review: Large-scale indirect measurements for enteric methane emissions in dairy cattle: A review of proxies and their potential for use in management and breeding decisions. J. Dairy Sci. 100:2433-2453.

Qin, L. X., H. C. Huang, and C. B. Begg. 2016. Cautionary note on using cross-validation for molecular classification. J. Clin. Oncol. 34:3931-3938

Roberts, D. R., V. Bahn, S. Ciuti, M. S. Boyce, J. Elith, G. Guillera-Arroita, S. Hauenstein, J. J. Lahoz-Monfort, B. Schröder, W. Thuiller, D. I. Warton, B. A. Wintle, F. Hartig, and C. F. Dormann. 2017. Cross-validation strategies for data with temporal, spatial, hierarchical, or phylogenetic structure. Ecography 40:913929.

Rutten, M. J. M., H. Bovenhuis, J. M. L. Heck, and J. A. M. van Arendonk. 2011. Predicting bovine milk protein composition based on Fourier transform infrared spectra. J. Dairy Sci. 94:5683-5690.

Rutten, M. J. M., H. Bovenhuis, K. A. Hettinga, H. J. F. van Valenberg, and J. A. M. van Arendonk. 2009. Predicting bovine milk fat composition using infrared spectroscopy based on milk samples collected in winter and summer. J. Dairy Sci. 92:6202-6209.

SAS Institute. 2011. SAS/STAT User's Guide: Release 9.3. SAS Inst., Cary, NC.

Shetty, N., G. Difford, J. Lassen, P. Løvendahl, and A. J. Buitenhuis. 2017. Predicting methane emissions of lactating Danish Holstein cows using Fourier transform mid-infrared spectroscopy of milk. J. Dairy Sci. 100:9052-9060.

Soyeurt, H., P. Dardenne, F. Dehareng, G. Lognay, D. Veselko, M. Marlier, C. Bertozzi, P. Mayeres, and N. Gengler. 2006. Estimating fatty acid content in cow milk using mid-infrared spectrometry. J. Dairy Sci. 89:3690-3695.

van Engelen, S., H. Bovenhuis, P. P. J. van der Tol, and M. H. P. W. Visker. 2018. Genetic background of methane emission by Dutch Holstein Friesian cows measured with infrared sensors in automatic milking systems. J. Dairy Sci. 101:2226-2234.

van Gastelen, S., H. Mollenhorst, E. C. Antunes-Fernandes, K. A. Hettinga, G. G. van Burgsteden, J. Dijkstra, and J. L. W. Rademaker. 2018. Predicting enteric methane emission of dairy cows with milk Fourier-transform infrared spectra and gas chromatography-based milk fatty acid profiles. J. Dairy Sci. 101:5582-5598.

Vanlierde, A., H. Soyeurt, N. Gengler, F. G. Colinet, E. Froidmont, M. Kreuzer, F. Grandl, M. Bell, P. Lund, D. W. Olijhoek, M. Eugene, C. Martin, B. Kuhla, and F. Dehareng. 2018. Development of an equation for estimating methane emissions of dairy cows from milk Fourier transform mid-infrared spectra by using reference data obtained exclusively from respiration chambers. J. Dairy Sci. 101:7618-7624.

Vanlierde, A., M. L. Vanrobays, F. Dehareng, E. Froidmont, H. Soyeurt, S. McParland, E. Lewis, M. H. Deighton, F. Grandl, M. Kreuzer, B. Gredler, P. Dardenne, and N. Gengler. 2015. Hot topic: Innovative lactation-stage-dependent prediction of methane emissions from milk mid-infrared spectra. J. Dairy Sci. 98:5740-5747.

Wall, E., G. Simm, and D. Moran. 2010. Developing breeding schemes to assist mitigation of greenhouse gas emissions. Animal 4:366-376.

Wang, Q., A. Hulzebosch, and H. Bovenhuis. 2016. Genetic and environmental variation in bovine milk infrared spectra. J. Dairy Sci. 99:6793-6803.

Wold, S., H. Martens, and H. Wold. 1983. The multivariate calibration problem in chemistry solved by the PLS method. Page 286-293 in Proc. Conf. on Matrix Pencils, Lecture Notes in Mathematics. A. Ruhe and B. Kagstrom, ed. Springer, Heidelberg, Germany.

Wu, L., P. W. G. Koerkamp, and N. W. Ogink. 2016. Temporal and spatial variation of methane concentrations around lying cubicles in dairy barns. Biosyst. Eng. 151:464-478. 